\title{
Chloro-s-triazine Dyes as Vital Markers in Monkeys
}

\author{
JAMES A. MC NAMARA, JR. and M. CHRISTINE MC BRIDE \\ Department of Anatomy and Center for Human Growth and Development, \\ University of Michigan, Ann Arbor, Michigan 48104, USA
}

Nine mono- and di-chloro-s-triazine (Procion) dyes (Table) have been tested for possible use as vital markers in rhesus monkeys (Macaca mulatta). Goland and Grand ( $A m J$ Phys Anthropol 29:201-218, 1968), Prescott, Mitchell, and Fahmy (Am J Phys Anthropol 29:219-224, 1968), and Seiton and Engel (AmJ Anat 126: $373-391,1969$ ) have demonstrated that certain types of reactive dyes are preserved in decalcified sections and act as indicators of osseous growth and growth of the dentition.

In this study, each dye was tested for consistency, intensity of marking, and toxic effects. Two to five of the dyes were tested in each of the 36 monkeys; 127 doses (which ranged from 50 to $150 \mathrm{mg} / \mathrm{kg}$ of body weight) were administered by multiple injections at four-week intervals. The dyes were injected intravenously in $30 \mathrm{ml}$ sterile water at a rate of $2 \mathrm{ml} /$ minute. The monkeys were killed later by formaldehyde solution (Formalin) perfusion and blocks from the temporomandibular joint, gonial angle, and the body of the mandible were decalcified in formic acid, embedded in celloidin, and sectioned at 10 to 30 micrometers.

Brilliant red H-8BS and brilliant purple $\mathrm{H}$ 3RS were the most effective, because lines of incremental growth were observed easily in newly formed bone and dentin in the unstained decalcified sections. Brilliant orange M-GS was less distinct, and it stained muscle fibers, bone,

This study was supported in part by USPHS Grants HD-02272 and DE-03610.

Received for publication October 10, 1972. and dentin. Olive green M-3GS also was an adequate vital marker, but occasional lethal side effects contraindicated its routine use in the monkey. Incremental lines of brilliant red M-8BS could be observed faintly in the sections, but these lines were difficult to differentiate from those of brilliant red $\mathrm{H}-8 \mathrm{BS}$. The other dyes tested (Table) were unsatisfactory.

A dose of $50 \mathrm{mg} / \mathrm{kg}$ body weight provided adequate staining intensity. Higher doses of various dyes led occasionally to vomiting, loss of weight, and in a few instances, to the death of the monkey.

Thus, this study demonstrated that chloro-striazine dyes brilliant red H-8BS, brilliant purple H-3RS, and brilliant orange M-GS can be used routinely in nonhuman primates as vital markers of osseous growth and growth of the dentition.

TABLE

(Procion) Dyes Tested

\begin{tabular}{lc}
\hline \hline \multicolumn{1}{c}{ Dye } & $\begin{array}{c}\text { Consistency } \\
\text { and Intensity } \\
\text { of Staining }\end{array}$ \\
\hline Brilliant red H-8BS & $\begin{array}{l}\text { Excellent } \\
\text { Brilliant purple H-3RS }\end{array}$ \\
Brilliant orange M-GS & Excellent \\
Olive green M-3GSA & Good \\
Brilliant red M-8BS & Food* \\
Brilliant blue H-5GS & Poor \\
Brilliant yellow M-4GS & Poor \\
Blue M-3GS & Poor \\
Grey M-GS & Poor \\
\hline
\end{tabular}

* Toxic side-effects. 